\title{
MATHEMATICAL AND COMPUTATIONAL MODELLING IN MATLAB FOR THE STUDY OF AN ORC SOLAR SYSTEM
}

\author{
Gabriela Amaral', Mariana Araújo², Leonilde Varela 3 \\ 1,2,3 University of Minho, Department of Production and Systems \\ gabi35734@live.com.pt, araujo.mc29@gmail.com, leonilde@dps.uminho.pt
}

\begin{abstract}
The main objective of this paper was to acquire the necessary thermodynamic knowledge in order to perform a thermodynamic and economic analysis of a solar ORC system of capacity of 10KW. For this, a model and computer program were developed in Matlab R2008a, version 7.6.0, which analyses the efficiency of the collector based on the gross solar radiation introduced and the efficiency of the ORC cycle against the power of the respective radiation. Based on the behaviour of the collector and the ORC cycle, the program returns as outputs the area and quantity of manifold required for the desired power.

Through this study it can be concluded that for the best scenario, the collector area required is $1044.1 \mathrm{~m} 2$ and collector 590 respectively. The annual profit is $48360 € /$ year and an 8 year payback for the initial investment with the vacuum tube collectors.
\end{abstract}

Keywords: Organic Rankine Cycle, Solar Collector Vacuum Tube, ORC Solar System, r-245fa.

\section{Introduction}

The main subject of this work is the study of the behaviour of an Organic Rankine thermodynamic cycle of a solar thermal unit with a capacity of up to $10 \mathrm{~kW}$. To this end, global solar radiation data referring to the island of Terceira - Açores is used, provided by Mr. Paulo Fialho [1].

The system consists of a vacuum tube solar collector coupled to an organic Rankine cycle.

The vacuum tube solar collector receives the solar radiation, and the power charged by it is transmitted to the boiler. The fluid that serves as the conductor of the respective heat is the water, which always circulates in a liquid state. For the study, the characteristics of a collector marketed by the company RenovaSolar were used, taking into account its proposal.

The basic Rankine cycle is an ideal cycle for steam power cycles, consisting of a boiler, a turbine, a condenser and a pump. The water, conventional working fluid, is heated in the boiler and subsequently expanded isoentropically in the turbine, responsible for energy production. Heat rejection at constant pressure occurs in the condenser, which is useful for outdoor heating. In the pump an isentropic compression occurs up to the operating pressure of the boiler.

The Organic Rankine cycle differs in the conventional cycle only in the working fluid. The system takes advantage of the expansive and regressive potentialities of its vaporization and condensation. It uses an organic medium, in this case study R-245fa, which has a slope in the positive steam saturation curve, which characterizes it as a dry fluid and goes to the gaseous state at low temperature. In this type of fluids, the specific vaporization of the fluid is smaller, which promotes a low fall of the enthalpy in the turbine.

The whole process works at low pressure and does not require the use of high pressure technologies, which means a high cost. The great advantage lies in the fact that the temperatures required to make the method efficient are relatively low.

The use of Rankine Organic cycle is broad in the area of energy, namely in the production of electricity from energy from biomass, geothermal and solar. It is used as support for other processes or as a means of saving waste.

For small scale applications, the high temperatures used in thermal plants based on the conventional Rankine cycle are not economical. The organic Rankine cycle (ORC) is a substitute technology, applicable in small applications such as residential and commercial buildings, reverse osmosis (RO) desalination processes, utilization of industrial waste heat, water pumping, steam compression chillers, among others.

The authors Nafey \& Sharaf, in 2010 [2] and the authors in [3] are of the opinion that ORC solar systems have great potential in remote areas, in the face of development, where sunshine is high and abundant. 


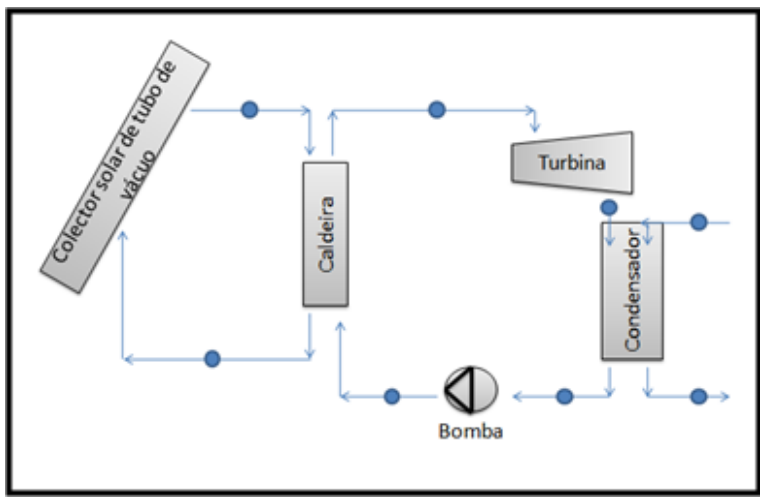

Figure 1: The ORC solar system scheme used in this study

In order to facilitate the study of the behaviour of the system against global radiation variation, a program was developed in Matlab R2008a [4], version 7.6.0. Through this, a numerical method of the system was created in order to facilitate the numerical calculations. For this, several thermodynamic equations were used. The program facilitates the study of the system in terms of execution time and calculations, given the various working conditions imposed by the user.

The main objective is to perform a sensitivity analysis of the system, at the level of the collector and the ORC cycle, against a given solar radiation $(\mathrm{w} / \mathrm{m} 2$ ) and determine the best conditions for the system to operate, in order to optimize the thermal efficiency of the ORC cycle. This is done by using the developed model and program, with which the area and the quantity of collectors required for the desired power are obtained.

\section{Literature Review}

Alternative applications based on renewable energies (solar, wind, biomass and geothermal energy) in electricity production are becoming increasingly important and with greater attention as a consequence of the fossil fuel crisis.

In recent years, many researchers have been working on developing new thermodynamic solar cycles or improving the performance of existing ones.

Projects of high enthalpy systems based on solar energy have been proposed and developed, such as parabolic trough, linear single-axis Fresnel compact reflector and parabolic dishes and tower systems distributed in two different areas of axis technologies. However, these complex systems require high costs and high temperatures of solar thermal systems and are not yet viable especially in developing countries. At the same time, technologies based on the same principle but low-mid enthalpy have been developed and with improvements in the results obtained [5].
Solar ORC cycles for combined production of electricity and heat have enormous potential to become competitive with fossil fuels, especially natural gas [5].

Ultimately, there is a growing concern about the use of waste heat in order to reduce its environmental impact. The availability of geothermal resources and solar energy is increasing. These are classified as low enthalpy sources. As a consequence, their use in the recovery of waste heat and its potential to reduce the consumption of fossil fuels and to soften environmental problems has become increasingly important.

Conventional steam cycles do not have the best performance for this task. The use of the ORC cycle in the use of waste heat is more advantageous, has an economic use of energy sources, leads to small systems and reduces emissions of $\mathrm{CO}, \mathrm{CO} 2, \mathrm{NOx}$ and other atmospheric pollutants [6].

The ORC cycle can be characterized as the only technology that has proven to produce ranges from a few KW up to 1MW. Although it is related to low efficiencies, new applications of this technology have been the subject of study, due to its possibility of using low level residual heat from other processes $[7,8]$.

The combination of the ORC cycle with heat recovery processes from biogas or micro-CHP offers promising low-cost solutions in decentralized applications. The high cost and fuel shortages make these applications even more attractive $[7,8]$.

The introduction of the ORC process into a reverse osmosis desalination system from solar energy provides a solution to areas where there is a shortage of potable water [3].

Another aspect to be considered, referred by several authors, is the type of fluid and the different working conditions to which the cycle is subject, which results in improved performance.

According to the author in [9] the highest system efficiency is related to the choice of means of organic adequate communication and depends on the application of the ORC cycle (level of heat source temperature), and the parameters on which the medium operates.

The selection of the working fluid for the Organic Rankine cycle is an important factor to consider and is very dependent on the target application, the working conditions and even the criteria taken into account $[10,11]$.

In the research developed by the author in [12, 13] the vacuum tube manifold proved to be efficient in low-mid enthalpy systems. On the other hand, R$245 \mathrm{fa}$ has been shown to be a viable, acceptable performance type for low-mid enthalpy ORC solar cycles. In this type of applications, the R-245fa exhibits good thermodynamic properties favourable to good conversion efficiency [14]. A computational tool developed by the authors in [15] allows the user 
to get the desired results, obtain optimum solutions and perform a sensitivity analysis in a short time.

\section{Problem Description}

In order to study the behaviour of an ORC System of $10 \mathrm{~kW}$ capacity, a global solar radiation database was used for Terceira Island - Azores, 2010.

Some formalisms and tools can be used for developing safe software for critical systems [16-23].

In this study, a mathematical modelling and a computational program were developed in Matlab R2008a, version 7.6 [4], in order to simulate several cases for different operating conditions of the collector and the ORC cycle, and to evaluate the respective efficiencies, power outputs of the turbine and capacitor, as well as the area and quantity of collectors required. In order to carry out an economic analysis, to determine the payback of the investment.

\section{- Model and Computational Program}

The developed program provides a sensitivity analysis and optimizes the time in obtaining results for the ORC solar system. In addition, it minimizes calculation errors.

The computational tool was developed in Matlab environment - version 7.6.0 (r2008a) [4]. The code was written in an M-file is a text file that adds a code instruction set [24] and the GUI created the GUI (Graphical User Interface).

The following figure shows the graphical interface of the program developed for ORC solar system analysis. It allows the user to enter the necessary parameters, called inputs, and in the same environment to obtain the results, the outputs.

Each parameter is identified objectively, followed by the respective field, where the user must enter its value, and the corresponding unit.

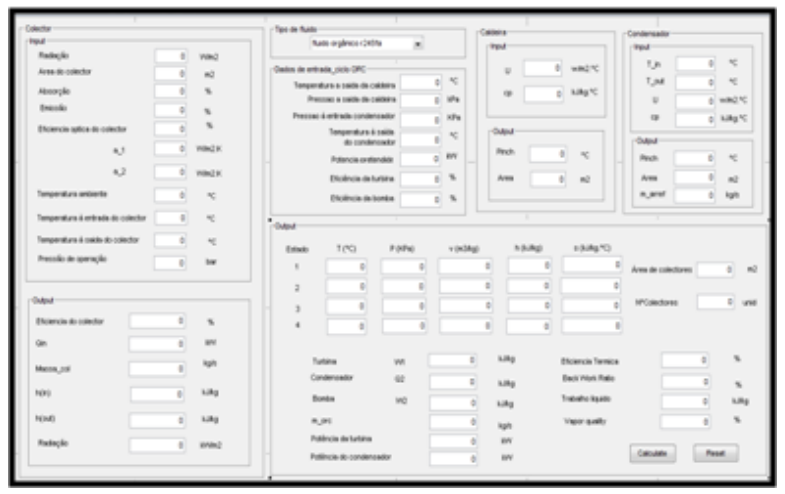

Figure 2: Graphical interface of the computational tool of the ORC solar system.

All of the input fields have the enable feature in the "on" state and outputs, in the "inactive. This ensures that the input fields are available to enter values and the output fields are only for visualization of the results.

The graphical interface consists of six main panels, of which three have two secondary panels, one for the respective inputs and another for the outputs. The panel titled "Fluid Type" contains a popup menu, where you can select the fluid you want to operate in the ORC cycle. The "Output" panel returns the most relevant results from the ORC solar system.

The user clicking the button popup menu is shown three types of fluids: H 20 R-245fa organic fluids and the R-134a.

Once the user is selecting the type of fluid, the units of the thermodynamic properties change. This is due to the fact that the properties in the respective thermodynamic tables are in different units.

When the R-245fa fluid is selected, the pressure appears in $(\mathrm{KPa})$ and the entropy in $\left(\mathrm{kJ} / \mathrm{kg}{ }^{0} \mathrm{C}\right)$.

The first cycle in the program's $\mathrm{M}$-file, when the "Calculate" button is pressed, is that of the solar collector.

The temperature and operating pressure values are read. If they are not within the intended limits, the user is approached with an error message.

The temperature at the inlet of the manifold should be less than the outlet temperature and the operating pressure should vary between 0.04 and 220.9 bar so that the values can be read in the respective table.

The efficiency of the collector is calculated based on formula 20 , mentioned in the previous chapter. If the efficiency value is negative, it means that the manifold does not work. The user is alerted with an error message.

Subsequently, the program checks whether the water, which operates in the manifold, is in the liquid state. For this, it uses the saturation temperature reading for operating pressure. If the water is not in the liquid state, an error message appears.

The saturation temperature is calculated in the sub-computation "Temp_sat". Based on the result, the program compares the temperature at the outlet of the manifold therewith. Calculation of the mass circulating in the manifold is done taking into account the enthalpy property related to its inlet and outlet temperatures. The main function uses a subfunction to thereby obtain the enthalpies inherent to the collector temperatures.

The program uses the equations mentioned in the previous chapter to calculate the parameters considered as outputs of the collector.

In order to perform the calculation of the desired parameters as outputs, it is necessary to read, according to the values of the parameters entered, in the thermodynamic tables of the selected fluid. To do this, each fluid has sub-functions with the cycles appropriate to the respective reading for the different tables existing for the same fluid. 
In state 1 , the saturation pressure for the respective introduced fluid is calculated in a subfunction. The program checks whether the fluid is in the gaseous state, based on the saturation pressure, and the pressure within the limits of the table pressures. If any of these cases do not occur, the user is alerted with an error message.

The values for the specific volume, enthalpy and entropy are returned by a sub-function appropriate to the selected fluid type. This sub-function has the code for reading the table appropriate to the state of the fluid. The reading is made based on the boiler outlet pressure and the temperature. The variables used to read the tables are the pressure at the input of the capacitor and the state 1 entropy. The subfunction returns the temperature, the specific volume and the enthalpy. In state 3 , the program checks if the temperature at the output of the capacitor, inserted by the user is lower than the temperature obtained for state 2 . The user will be notified with an error message in case the condition is not checked.

The specific volume, enthalpy and entropy are returned to the main function by their sub-function. The above properties are read based on the outlet temperature and the inlet pressure of the condenser. In state 4 , the pressure at the boiler output and the entropy at state 3 are the properties used for reading the tables. The respective sub-function of state 4 returns the specific volume, temperature and enthalpy to the same state. With the necessary properties, the outputs for the ORC cycle, boiler and condenser present in the graphical interface are calculated, based on the formulas mentioned in the previous chapter. After the calculations have been carried out, the program will print them on the screen.

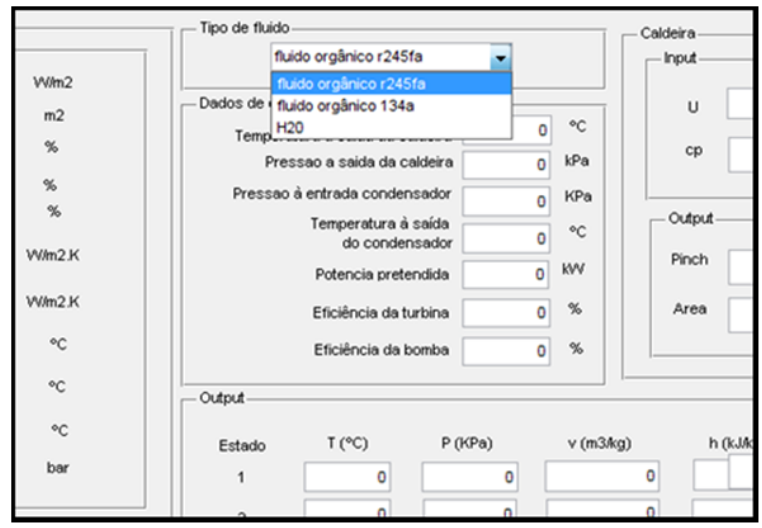

Figure 3: Types of fluids presented to the user.

\section{- Simulated Cases}

The following table presents the parameters used in the program to simulate the several cases presented below.
The parameters relating to the manifold were selected based on technical manual provided by the company RenovaSolar (test collector according to EN 12975 to $1.2: 2006$ ) [25].

The calorific value at constant water pressure was calculated by interpolation of the author's table A-9 [26,27] and the efficiencies presented by the authors in [28].

The remaining parameters were consistently assumed based on studies carried out on the same theme.

A temperature at the outlet of the collector of $95{ }^{\circ} \mathrm{C}$ was assumed taking into account the maximum operating temperature of the manifold and the temperature at its inlet at. In the technical manual of the manifold, it is mentioned that the maximum stagnation temperature of this is $200.3{ }^{\circ} \mathrm{C}$ and is not mentioned in it, damage of the material if the working liquid reaches values between the maximum operating temperature and the maximum stagnation temperature, and in some cases below, a temperature at the outlet of the collector of $158^{\circ} \mathrm{C}$.

Table 1. Fixed parameters used in the simulation of the various cases presented.

\begin{tabular}{|c|c|c|}
\hline \multicolumn{3}{|c|}{ fixed parameters } \\
\hline to 1 & 1.529 & $\mathrm{~W} / \mathrm{m}^{2}$ \\
\hline A_2 & 0.0166 & $\mathrm{~W} / \mathrm{m}^{2}$ \\
\hline Optical efficiency of the collector & 73.4 & $\%$ \\
\hline Area of a manifold unit & 1.77 & $2 \mathrm{~m}$ \\
\hline $\begin{array}{l}\text { Coefficient of absorption of the } \\
\text { collector }\end{array}$ & 95 & $\%$ \\
\hline $\begin{array}{l}\text { Coefficient of emission of the } \\
\text { collector }\end{array}$ & $\begin{array}{r}\text { Referring to } \\
\text { Fig. }\end{array}$ & $\%$ \\
\hline Turbine efficiency & 75 & $\%$ \\
\hline Pump efficiency & 75 & $\%$ \\
\hline required power & 10 & KW \\
\hline cp (H20) & 4.1788 & $\begin{array}{l}\mathrm{kJ} / \\
\mathrm{kg} \cdot{ }^{\circ} \mathrm{C}\end{array}$ \\
\hline $\begin{array}{l}\text { Cooler temperature at collector } \\
\text { inlet }\end{array}$ & 20 & ${ }^{\circ} \mathrm{C}$ \\
\hline $\begin{array}{l}\text { Cooling temperature at the } \\
\text { collector outlet }\end{array}$ & 36 & ${ }^{\circ} \mathrm{C}$ \\
\hline Ambient temperature in winter & 15 & ${ }^{\circ} \mathrm{C}$ \\
\hline Ambient temperature in summer & 20 & ${ }^{\circ} \mathrm{C}$ \\
\hline Collector operating pressure & 6 & Pub \\
\hline
\end{tabular}

The critical point of R-245fa according to the authors in [29] is reached at a temperature of $154^{\circ} \mathrm{C}$ and a pressure of $3634 \mathrm{KPa}$. Based on this and the phase to which the liquid must be for the different states of the ORC cycle, the values mentioned for the various cases are assigned for the temperature at the exit of the boiler and the condenser and the respective pressures. The output tables do not have all the outputs obtained from the simulation of the various cases, only the most relevant ones are presented. 


\section{Case 1}

Table 2. Inputs used in case simulation 1.

\begin{tabular}{|c|c|c|}
\hline \multicolumn{3}{|c|}{ Collector } \\
\hline Inlet temperature & 40 & ${ }^{\circ} \mathrm{C}$ \\
\hline Outlet temperature & 95 & ${ }^{0} \mathrm{C}$ \\
\hline \multicolumn{3}{|c|}{ ORC cycle } \\
\hline Temperature at the boiler outlet & 80 & ${ }^{0} \mathrm{C}$ \\
\hline Boiler outlet pressure & 700 & $\mathrm{KPa}$ \\
\hline Condenser output temperature & 30 & ${ }^{\circ} \mathrm{C}$ \\
\hline Pressure at the condenser inlet & 300 & $\mathrm{KPa}$ \\
\hline
\end{tabular}

Table 3. Outputs obtained from simulation of case 1

\begin{tabular}{|c|c|c|c|c|c|}
\hline Days & \begin{tabular}{|c|} 
Floor \\
radiation (W/ \\
$\mathrm{m} 2)$
\end{tabular} & $\begin{array}{c}\text { And } f_{-} \text {col } \\
(\%)\end{array}$ & $\begin{array}{c}\text { And f_orc } \\
(\%)\end{array}$ & Area $\left(m^{2)}\right.$ & No.Colectors \\
\hline January 1st & 229.52 & 12.4 & \multirow{5}{*}{5.07} & 59492.60 & 33612 \\
\hline 2 January & 713.91 & 53.8 & & 1015.04 & 574 \\
\hline January 6 & 572.85 & 49 & & 1526.90 & 863 \\
\hline July 6 & 1327.33 & 64.2 & & 383.36 & 217 \\
\hline July 11 & 965.62 & 60.7 & & 588.57 & 333 \\
\hline
\end{tabular}

\section{Case 2}

Table 4. Inputs used in case simulation 2.

\begin{tabular}{|l|r|r|}
\hline \multicolumn{3}{|c|}{ Collector } \\
\hline \multicolumn{1}{|c|}{ ORC cycle } & 40 & ${ }^{\circ} \mathrm{C}$ \\
\hline Inlet temperature & 95 & ${ }^{\circ} \mathrm{C}$ \\
\hline Outlet temperature & 80 & ${ }^{\circ} \mathrm{C}$ \\
\hline Temperature at the boiler outlet & & \\
\hline & 700 & $\mathrm{KPa}$ \\
\hline Boiler outlet pressure & 30 & ${ }^{\circ} \mathrm{C}$ \\
\hline Condenser output temperature & & \\
\hline & 200 & $\mathrm{KPa}$ \\
\hline
\end{tabular}

Table 5. Outputs obtained from case 2 simulation.

\begin{tabular}{|c|c|c|c|c|c|}
\hline Days & \begin{tabular}{|c|} 
Floor \\
radiation (W / \\
$\mathrm{m} 2)$
\end{tabular} & $\begin{array}{l}\text { And f_col } \\
(\%)\end{array}$ & $\begin{array}{l}\text { And f_orc } \\
\text { (\%) }\end{array}$ & Area $\left(m^{2)}\right.$ & No.Colectors \\
\hline January 1st & 229.52 & 12.4 & \multirow{5}{*}{7.60} & 40263.00 & 22748 \\
\hline 2 January & 713.91 & 53.8 & & 686.50 & 389 \\
\hline 6 January & 572.85 & 49 & & 1033.36 & 584 \\
\hline July 6 & 1327.33 & 64.2. & & 259.45 & 147 \\
\hline July 11 & 965.62 & 60.7 & & 396.33 & 226 \\
\hline
\end{tabular}

\section{Case 3}

Table 6. Inputs used in simulation of case 3.

\begin{tabular}{|c|c|c|}
\hline \multicolumn{3}{|c|}{ Collector } \\
\hline Inlet temperature & 40 & ${ }^{0} \mathrm{C}$ \\
\hline Outlet temperature & 158 & ${ }^{\circ} \mathrm{C}$ \\
\hline \multicolumn{3}{|c|}{ ORC cycle } \\
\hline Temperature at the boiler outlet & 153 & ${ }^{\circ} \mathrm{C}$ \\
\hline Boiler outlet pressure & 1650 & $\mathrm{KPa}$ \\
\hline Condenser output temperature & 30 & ${ }^{\circ} \mathrm{C}$ \\
\hline Pressure at the condenser inlet & 300 & $\mathrm{KPa}$ \\
\hline
\end{tabular}

Table 7. Outputs obtained from case simulation 3.

\begin{tabular}{|c|c|c|c|c|c|}
\hline Days & \begin{tabular}{|c} 
Floor \\
radiation (W / \\
m2)
\end{tabular} & $\begin{array}{c}\text { And f_col } \\
(\%)\end{array}$ & $\begin{array}{c}\text { And f_orc } \\
(\%)\end{array}$ & Area $\left(\mathrm{m}^{2}\right)$ & No.Colectors \\
\hline January 1st & 229.52 & & \multirow{5}{*}{8.94} & & \\
\hline 2 January & 713.91 & 35.2 & & 1209.32 & 729 \\
\hline 6 January & 572.85 & 25.8 & & 2914.75 & 1692 \\
\hline July 6 & 1327.33 & 54.6 & & 287.74 & 163 \\
\hline July 11 & 965.62 & 47.6 & & 521.15 & 295 \\
\hline
\end{tabular}

\section{Case 4}

Table 8. Inputs used in case 4 simulation

\begin{tabular}{|c|c|c|}
\hline \multicolumn{3}{|c|}{ Collector } \\
\hline Inlet temperature & 40 & ${ }^{\circ} \mathrm{C}$ \\
\hline Outlet temperature & 158 & ${ }^{\circ} \mathrm{C}$ \\
\hline \multicolumn{3}{|c|}{ ORC cycle } \\
\hline Temperature at the boiler outlet & 153 & ${ }^{\circ} \mathrm{C}$ \\
\hline Boiler outlet pressure & 1650 & $\mathrm{KPa}$ \\
\hline Condenser output temperature & 30 & ${ }^{\circ} \mathrm{C}$ \\
\hline Pressure at the condenser inlet & 200 & $\mathrm{KPa}$ \\
\hline
\end{tabular}

Table 9. Outputs obtained from case 4 simulation

\begin{tabular}{|c|c|c|c|c|c|}
\hline Days & \begin{tabular}{|c|} 
Floor \\
radiation (W / \\
m2)
\end{tabular} & $\begin{array}{c}\text { And f_col } \\
(\%)\end{array}$ & $\begin{array}{c}\text { And f_orc } \\
(\%)\end{array}$ & Area $\left(\mathrm{m}^{2)}\right.$ & No.Colectors \\
\hline January 1st & 229.52 & & \multirow{5}{*}{11.23} & & \\
\hline 2 January & 713.91 & 35.2 & & 1044.10 & 590 \\
\hline 6 January & 572.85 & 25.8 & & 2425.16 & 1371 \\
\hline July 6 & 1327.33 & 54.6 & & 233.01 & 132 \\
\hline July 11 & 965.62 & 47.6 & & 422.03 & 239 \\
\hline
\end{tabular}

\section{Case 5}

Table 10. Inputs used in simulation of case 5

\begin{tabular}{|c|c|c|}
\hline \multicolumn{3}{|l|}{ Collector } \\
\hline Inlet temperature & 40 & ${ }^{\circ} \mathrm{C}$ \\
\hline Outlet temperature & 158 & ${ }^{\circ} \mathrm{C}$ \\
\hline \multicolumn{3}{|l|}{ ORC cycle } \\
\hline Temperature at the boiler outlet & 148 & ${ }^{\circ} \mathrm{C}$ \\
\hline Boiler outlet pressure & 1650 & $\mathrm{KPa}$ \\
\hline Condenser output temperature & 30 & ${ }^{\circ} \mathrm{C}$ \\
\hline Pressure at the condenser inlet & 300 & $\mathrm{KPa}$ \\
\hline
\end{tabular}

Table 11. Outputs obtained from simulation of case 5

\begin{tabular}{|c|c|c|c|c|c|}
\hline Days & $\begin{array}{c}\text { Floor } \\
\text { radiation (W/ } \\
\mathrm{m} 2)\end{array}$ & $\begin{array}{c}\text { And f_col } \\
(\%)\end{array}$ & $\begin{array}{c}\text { And f_orc } \\
(\%)\end{array}$ & Area $\left(\mathrm{m}^{2}\right)$ & No.Colectors \\
\hline January 1st & 229.52 & & \multirow{5}{*}{8.95} & & \\
\hline 2 January & 713.91 & 35.2 & & 1285.67 & 727 \\
\hline 6 January & 572.85 & 25.8 & & 2986.25 & 1688 \\
\hline July 6 & 1327.33 & 54.6 & & 286.92 & 163 \\
\hline July 11 & 965.62 & 47.6 & & 519.67 & 294 \\
\hline
\end{tabular}




\section{Case 6}

Table 12. Inputs used in simulation of case 6

\begin{tabular}{|l|r|r|}
\hline \multicolumn{3}{|c|}{ Collector } \\
\hline Inlet temperature & 40 & ${ }^{\circ} \mathrm{C}$ \\
\hline Outlet temperature & 158 & ${ }^{\circ} \mathrm{C}$ \\
\hline \multicolumn{3}{|c|}{ ORC cycle } \\
\hline Temperature at the boiler outlet & 148 & ${ }^{\circ} \mathrm{C}$ \\
\hline & & \\
Boiler outlet pressure & 1650 & $\mathrm{KPa}$ \\
\hline Condenser output temperature & 30 & ${ }^{\circ} \mathrm{C}$ \\
\hline Pressure at the condenser inlet & 200 & $\mathrm{Kp}$ \\
\hline
\end{tabular}

Table 13. Outputs obtained from the simulation of case 6.

\begin{tabular}{|c|r|r|r|r|r|}
\hline Days & $\begin{array}{c}\text { Floor } \\
\text { radiation (W/ } \\
\text { m2) }\end{array}$ & And __ol (\%) & $\begin{array}{c}\text { And f_orc } \\
\text { (\%) }\end{array}$ & Area (m 2) & No.Colectors \\
\hline January 1st & 229.52 & & & & \\
\hline 2 January & 713.91 & 35.2 & & 1040.68 & 588 \\
\hline 6 January & 572.85 & 25.8 & \multirow{2}{*}{11.26} & 2417.21 & 1366 \\
\hline July 6 & 1327.33 & 54.6 & & 232.25 & 132 \\
\hline July 11 & 965.62 & 47.6 & & 420.65 & 238 \\
\hline
\end{tabular}

The first day of January does not present results for the cases where the temperature at the entrance of the collector is $158^{\circ} \mathrm{C}$, because the radiation is not enough to activate the operation of the same. For cases $3,4,5$ and 6 , the program alerts the user of such a situation with an error message (Figure 4).

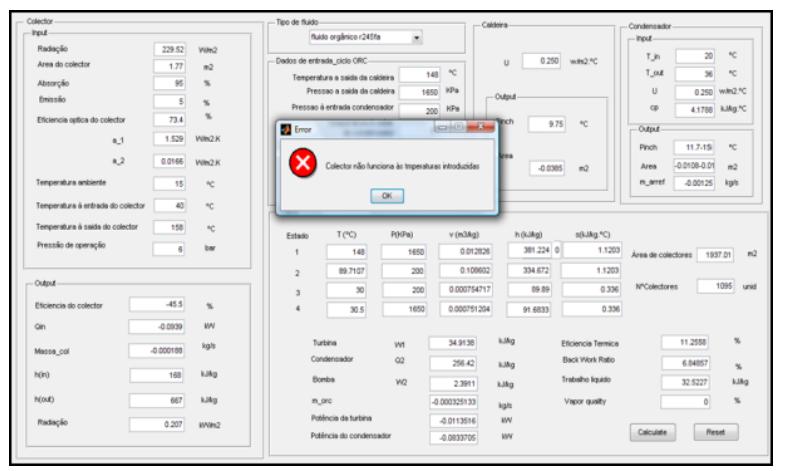

Figure 3: Error message occurred at January the first.

\section{Results Analysis}

Case 2 is a situation of optimization of the efficiency of the manifold based on the decrease of the pressure in the condenser of case 1 . There was an increase in the efficiency of the manifold from $5.07 \%$ to $7.60 \%$ as consequence of a decrease in the temperature of the steam. If the temperature at which the heat is discarded and an increase in liquid work and heat consumption.
The required area and the number of collectors decrease significantly.

In cases 3,4 and 5,6 the same situation occurs. The collector efficiency varies between $8.94 \%$ and $11.23 \%$ and between $8.95 \%$ and $11.26 \%$, respectively.

From case 3, the increase in temperature at the exit of the boiler implies increasing the temperature at the outlet of the collector in order to obey the 2 nd Law of Thermodynamics.

The optimization of the efficiency of the manifold affected by the increase in boiler pressure is done in case 3,4 with respect to case 1,2 . For the introduced pressure, the working fluid only reaches the gaseous state at higher boiler outlet temperatures. Raising the boiler operating pressure increases the boiling temperature and, in turn, the average temperature at which the heat is transferred to the steam, which is reflected in the increased efficiency of the manifold. With this optimization, efficiency varies between $5.07 \%$ and $8.94 \%$ in case 1 and 3 , and in case 2 and 4, efficiency is $7.60 \%$ and $11.23 \%$, respectively. In this way, a significant reduction in the area and number of collectors required is observed.

Overheating steam at higher temperatures is another method of optimizing cycle efficiency. This method is applied between cases 2, 5 and 4, 6 in which efficiency varies between $8.94 \%$ and $8.95 \%$ and between $11.23 \%$ and $11.25 \%$, respectively, and there is a small difference between the areas and the number of collectors Is not very significant.

With this method, the average temperature at which heat is transferred to the steam, the liquid work and the heat consumption increase. The increase of these parameters translates into an increase in the thermal efficiency of the cycle.

The best operating conditions of the cycle are verified in case 4 and 6, because they have higher efficiencies than the other cases Therefore, within the operating limits of the collector and based on the solar radiation supplied, the ORC solar system must be subject to the respective input parameters mentioned in Tables 14 and 15.

In case 4 , the temperature at the inlet of the collector is $158^{\circ} \mathrm{C}$ and the relative efficiency depending on the incident solar radiation varies between $25.8 \%$ and $35.2 \%$. The temperature at the boiler outlet is $153^{\circ} \mathrm{C}$ and the respective pressure is $1650 \mathrm{KPa}$. In the condenser, the temperature at its outlet is $30^{\circ} \mathrm{C}$ and the pressure is $200 \mathrm{KPa}$. The thermal efficiency obtained is of $11.23 \%$, the back work ratio of $6.73 \%$, the network of $33.14 \mathrm{~kJ} / \mathrm{kg}$, the power output by the turbine and condenser are of $0.027 \mathrm{~kW}$ and of $0.2 \mathrm{~kW}$, respectively. The required area collectors' incident radiation varies between $233.01 \mathrm{~m} 2-1044.10 \mathrm{~m} 2$ and the related amount between 132-1371. 
The remaining inputs are the same as those for the previous case. The thermal efficiency is $11.26 \%$, the back work ratio of $6.85 \%$, the network of $32.52 \%$, the power delivered by the turbine and the condenser are very close to those of case 4 . It is noted that the parameters referred to differ little those of the previous case. The required area and the quantity of collectors suffer a minor decrease.

It is important to note that cases 1 and 2 , although they have a lower thermal efficiency than the other cases, the efficiency of the solar collector is higher than the incident solar radiation, which is constant between the scenarios. In addition, the manifold operates at lower radiation levels.

According to Decree-Law no. 363/2007 of November 2, 2007 [30], the process under study can be considered as a micro-cogeneration, since it has a maximum capacity of less than $50 \mathrm{~kW}$. The ORC solar system is covered by the subsidized scheme as described for article 9, paragraph 2 of Decree-Law no. 118 - A/ 2010, of October 25, 2010 [31].

Taking into account the cases with the best performance in terms of thermal efficiency, the outputs are used in relation to turbine power, condenser power, total area and the number of collectors required, for January 2 and July 6, for the economic analysis of the ORC solar system under study. The price of $0.40 € / \mathrm{kW} . \mathrm{h}$ (Decree-Law no 118 -A/ 2010) [8] for the sale of electricity and the price of a SunPro collector with 10 Heat-Pipe vacuum tubes of $413.13 € /$ unit (TZ58 -1800, 2007)

According to Resolution $\mathrm{n} \times 01 / 2011$ [10], issued by the regulatory authority for energy services, the sale tariff to end customers of social Lusitaniagás applied to step 2 holders clients (221$500 \mathrm{~m} 2$ / year) is $0.0598 € / \mathrm{kW}$. In turn, this market at a unit cost of $0.0614 € / \mathrm{kW} . \mathrm{h}$.

The economic analysis is carried out for one year and, based on the total obtained; the payback of the investment in relation to the collectors is calculated.

Table 14. ORC solar system data required for economic analysis

\begin{tabular}{|l|r|r|r|r|r|}
\hline \multicolumn{1}{|c|}{ Day } & $\begin{array}{c}\text { Operating } \\
\text { Time }(\mathrm{h})\end{array}$ & Area $\left(\mathrm{m}^{2)}\right.$ & No.Colectors & $\begin{array}{c}\text { Turbine } \\
\text { power }(\mathrm{kW})\end{array}$ & $\begin{array}{c}\text { Condenser } \\
\text { power }(\mathrm{kW})\end{array}$ \\
\hline $\mathbf{2}$ & $\begin{array}{r}\text { Referring to } \\
\text { Fig. }\end{array}$ & 1044.1 & 590 & 0.027 & 0.20 \\
\hline January & Referring to & & & & \\
\hline July 6 & Fig. & 233.01 & 132 & 0.079 & 0.58 \\
\hline
\end{tabular}

The following table shows the days considered for each month of the year and the total number of days for the two stations considered, the "Winter/ Autumn" season and the "Spring/ Summer season".
Table 15. Months, respective days and seasons considered in the economic analysis

\begin{tabular}{|c|r|r|}
\hline Season & \multicolumn{1}{|c|}{ Months } & \multicolumn{2}{|c|}{ Days } \\
\hline \multirow{4}{*}{ Winter / Fall } & January & 31 \\
\cline { 2 - 3 } & February & 28 \\
\cline { 2 - 3 } & October & 31 \\
\cline { 2 - 3 } & November & 30 \\
\cline { 2 - 4 } & December & 31 \\
\hline \multirow{4}{*}{ Spring / } & Total & $\mathbf{1 5 1}$ \\
\cline { 2 - 4 } & March & 31 \\
\cline { 2 - 3 } & April & 30 \\
\cline { 2 - 3 } & May & 31 \\
\cline { 2 - 3 } & June & 30 \\
\cline { 2 - 3 } & July & 31 \\
\cline { 2 - 3 } & August & 31 \\
\cline { 2 - 3 } & September & 30 \\
\hline & Total & $\mathbf{2 1 4}$ \\
\hline
\end{tabular}

The daily monetary value in relation to the power output from the turbine and condenser is calculated on the basis of the following formulas [3236]:

- Turbine $(€ /$ day) $=$ Power is INSTANCE turbine $(\mathrm{kW}) *$ rate $(€ / \mathrm{kW} . \mathrm{h}) *$ collector operating time $(\mathrm{h}) *$ a necessary area of the Ria collectors (m2)

- Condenser (€/ day) = Power is INSTANCE condenser $(\mathrm{kW}) *$ rate $(€ / \mathrm{kW} . \mathrm{h}) *$ collector operating time $(\mathrm{h}){ }^{*}$ a necessary area of the Ria collectors $(\mathrm{m} 2)$

The total gain per year is calculated based on the daily income and the number of days for each season of the year considered in the study.

Tabela 16. Daily and annual income for the "Winter/ Autumn" season

\begin{tabular}{|c|c|c|c|}
\cline { 2 - 4 } \multicolumn{1}{c|}{} & Turbine & Condenser & Total \\
\cline { 2 - 4 } \multicolumn{1}{c|}{} & $€ /$ day & $€ /$ day & $€ /$ day \\
\hline Winter / Fall & 56.85 & 64.32 & 121.17 \\
\hline \multirow{2}{*}{ Total } & $€ /$ year & $€ /$ year & $€ /$ year \\
\cline { 2 - 4 } & 8584.22 & 9711.78 & 18296.00 \\
\hline
\end{tabular}

Table 17. Daily and annual income for the "Spring/ Summer" season

\begin{tabular}{|c|c|c|c|}
\cline { 2 - 4 } \multicolumn{1}{c|}{} & Turbine & Condenser & Total \\
\cline { 2 - 4 } \multicolumn{1}{c|}{} & $€ /$ day & $€ /$ day & $€ /$ day \\
\hline \multirow{2}{*}{ Spring / Summer } & 65.91 & 74.57 & 140,49 \\
\hline \multirow{2}{*}{ Total } & $€ /$ year & $€ /$ year & $€ /$ year \\
\cline { 2 - 4 } & 14105.64 & 15958.43 & 30064.08 \\
\hline
\end{tabular}

The area considered, for the calculation of the total cost per year of the following table, is the one of the 2 of January of the respective case considered, in a way to undersize the system. 
Table 18. Total annual income and investment amortization time

\begin{tabular}{|l|c|}
\cline { 2 - 2 } \multicolumn{1}{c|}{} & Total ( $€ /$ year) \\
\hline Winter / Fall & 18296.00 \\
\hline Spring / Summer & 30064.08 \\
\hline Total & 48360.08 \\
\hline Total price collectors $(€)$ & 243746.7 \\
\hline Years & Referring to Fig. \\
\hline
\end{tabular}

The power output from the condenser and the "Spring / Summer" station provides greater benefits. The conditions imposed for the temperature at the outlet of the condenser and pressure influence the results obtained, so the heat rejection process presents better results than in the production of electricity. The benefit shown for the power charged by the condenser is mentioned as an exempt cost payable on gas.

The gains for the season "Spring/ Summer" are larger in relation to the "Winter/ Autumn" season because its solar radiation in the collector is higher.

Taking into account the profit from the sale of electricity and what is earned by the consumer does not have cost the gas, the investment made with the vacuum tube solar collectors is amortized over eight years.

The method used in the economic analysis is simple and does not take into account a lot of detail, which influences the result of the payback. This is merely an estimate and not a concrete value.

\section{Conclusion}

The present work has as its subject the behaviour of an ORC system of $10 \mathrm{~kW}$ capacity, given the solar radiation incident on the receiver of the same.

In order to optimize the analysis time and to make it more reliable, avoiding the respective calculation errors system, a model was developed and computer program R2008a in Matlab, version 7.6 [4]. The main objective of the program was to simulate several cases of operating conditions for the collector and the ORC cycle, depending on the inserted solar radiation and evaluating such efficiencies, the power output turbine and the condenser. The area and the amount of required collectors were also studied and outputs provided by the same, for further economic analysis in order to determine the payback on investment with the collectors, with the best results.

The system consists of a vacuum tube solar collector, a boiler, a turbine, a condenser and a pump. The fluid circulating in the collector, in this case the water always circulates liquid receives heat through the solar radiation collector and transmits it to the ORC fluid circulating through the cycle boiler. In turn, the body fluid is expanded in the turbine isoentropicamente, responsible for the production of electricity. The heat rejection occurs at constant pressure in the condenser, which is used in a possible application of heat. Subsequently, there is a isentropically compressing the pump to the operating pressure of the boiler. Hit such pressure, a new cycle starts again.

The use of an organic fluid in the ORC cycle is what differs Organic Rankine cycle in a conventional cycle. In this study, the R-245fa is applied to the working fluid, the choice for this relates to the fact that the expanding system and regressive potential advantage in vaporization and condensation. Such fluid has a positive slope in the positive Ts diagram, which characterizes it as a dry fluid and passes to the gaseous state at low temperatures. Because of its specific vaporization is smaller, the decrease in enthalpy that occurs in the turbine is also reduced. Thus, the entire process occurs at low pressures which means a lower cost because it requires highpressure technology and you can get reasonable efficiency at low temperatures.

According to literature review conducted on the subject matter, the organic rankine cycle is applied to innovative solutions or as an integrated process in existing processes to maximize or to avoid waste [37-43]. These studies come up with the aim of finding solutions subjective solve the problem that the increase in population and the energy crisis level has caused to the environment and sustainable development. Consequently, the application of renewable energy in electricity generation, heat recovery and cold, have become increasingly important and has received greater attention.

The cycle Rankine Organic through the survey was applied to target geothermal solar hybrid systems, the author [3], in which the ORC cycle was designed for optimal use from a geothermal source intermediate and enthalpy, in order to increase power generation introduced a parabolic course. The system was analysed at four separate locations, Imperial, San Diego, Palermo, Pisa, where achieved levels of electricity before the annual insolation of $8.5 \%-9.5 \%$ and the cost of electricity level between $145-280 € / M W h$, depending on the system implementation site.

The POWERSOL project is the production of mechanical energy from solar energy, financed by the European Commission under the research program developed by the authors [43]. This was intended to optimize the cycle to produce the desired type of low energy-media enthalpy and this was carried out experimental tests on different types of working fluids and three solar collectors' prototypes in a possible application in Mediterranean areas, where the lack of electricity and the shortage of drinking water is scarce. With this study, the author concluded that PV systems are not the most suitable to meet the most basic needs of small communities in remote areas, as they are high 
cost technologies, low efficiency and typically use batteries for energy storage.

The authors $[3,28,44]$ study the ORC cycle combined with the reverse osmosis desalination process. In the opinion of these authors, this combination offers an alternative source for the production of drinking water in remote areas, where pollution and scarcity are accentuated. Ways to optimize the process with regard to the working fluid and the same operating conditions are studied.

The authors in [3] studied operating conditions of the solar system ORC that minimizes the opening area required per unit power for each type of fluid and the solar collector, into two types of configurations: direct production of steam and ORC regenerative cycle. It concludes that the dried fluids, regenerative cycle and the compound parabolic collector offer the best process efficiency.

According to the author [6], heat from the engines and from industrial processes can be utilized by using an ORC cycle, a suitable working fluid. Improved efficiencies are obtained and low decrease of enthalpy in the turbine promotes a simple design. Suggests this type of application to supply the demand of remote villages in developing countries and can still support geothermal energy or be the primary power source for vehicles.

The authors in $[7,8]$ pointed out in his work, that the combination of ORC cycle with heat recovery processes from biogas or micro - CHP, offers low cost promising solutions in decentralized applications.

The high cost and scarcity of fuel, makes these applications are even more attractive.

Taking into account the quotes from various authors, further improvement in the performance of this type of system under consideration is the type of fluid and working conditions to which it is subject. According to the author [9] the greatest system efficiency is related to the choice of means of organic appropriate communication and depends on the application of the ORC cycle (level heat source temperature), and the parameters the medium operates.

The selection of the working fluid for the organic rankine cycle is an important factor to consider, and is very dependent on the target application, the working conditions and even the criteria taken into account $[10,11]$.

In the research conducted by the authors in $[12,13,45]$, the vacuum tube collector showed to be effective in low-medium enthalpy systems. On the other hand, the R-245fa has proved a feasible type of fluid and acceptable performance, solar cycles ORC medium-low enthalpy. In such applications, the R245fa exhibits good thermodynamic properties favourable to good conversion efficiency [14].

The formulas used to calculate the parameters taken as outputs of the developed program were explained by the authors [26-28, 46]. The main parameters to evaluate the performance of the system mentioned by the first two authors were the thermal efficiency and the back work ratio. However, the sensitivity analysis was only referred to the former, because the latter varies in the same order as the previous one.

Taking into account the main irreversibilities that occurred in the system, according to the authors in [46], that influence their performance, states 2:04 of the system were affected by the isentropic efficiency of the turbine and the pump, respectively. The authors referred in the previous two paragraphs, refer several ways to optimize the efficiency of Rankine cycle [28, 46]. However, sensitivity analysis performed on only the following were used: decreasing the pressure in the condenser to increase the pressure in the boiler and the superheat steam turbine inlet at higher temperatures.

To study the collector according to the incident solar radiation performance, it used the characteristics of a vacuum tube solar collector sold by the company RenovaSolar. These types of collectors have a system Heat Pipe the Sunrain, high yield $[28,46]$. In the economic analysis applied the proposed amount of $€$ 413.13/ unit in the calculation of the investment with the collectors.

To determine certain thermodynamic parameters, such as temperature, pressure, specific volume, enthalpy and entropy is necessary to take into account certain criteria to use the correct table, where one must extract the same. In the model of programming and computer program these were considered and modelled after the author's theory $[26,27]$. If the values are not in the respective table, refers to the interpolation method. The supplied data of the year 2010 for the month of January and July, the incident radiation on Terceira Island were treated appropriately for the study. Was selected the most relevant days, which are the days 1, 2 and 6 January and the 6th and July 11th. The temporal resolution of such data corresponds to average values for a period of 5 seconds and with units in $\mathrm{mV}$. Subsequently, they were affected by a conversion factor $0.00525 \mathrm{MVM} 2 / \mathrm{W}$ [5]. To facilitate data analysis, based on a weighted average of the converted temporal resolution of 1 minute and removed if not all values that created value for the study.

The model and software developed within the respective theme, allows the user to perform a sensitivity analysis, optimizes time on results for the ORC system and minimizes miscalculations. A software tool was developed in Matlab R2008aversion 7.6.0 environment [4]. The code was written in an M-file is a text file that adds a code instruction set [24], and the GUI created the GUI (Graphical User Interface).

A sensitivity analysis of the data provided to the incident solar radiation was performed in the third island, the solar collector vacuum tube 10 SunPro 
heat-pipe tube and ORC system for solar simulated with said program. Finally, the economic analysis was based on the calculation of an average annual income for the system under study and obtained the repayment time period for the investment.

With performed a sensitivity analysis, it was found that the temperature in relation to the collector outlet temperature is the parameter which has the greatest influence on its efficiency. When the ambient temperature increases, the operating time of the collector is increased and the minimum radiation necessary for such decreases. On the other hand, the temperature at the collector output affects the yield of crescent-shaped manifold, that is, when this parameter is increased, the efficiency decreases.

Of cases and methods presented for optimizing the efficiency of the system, case 4 and 6 were what we had better results in terms of thermal efficiency of the system (11:23\% and 11:25\%) and in which the steam super-heater method was applied to higher temperatures at the entrance of the turbine. The difference between their efficiency is not very significant since the difference between the temperatures is only $10^{\circ} \mathrm{C}$.

The results for the day January 2 and July 6, Case 4, were used in the economic analysis. The first day represented the season "Winter/ Autumn" and the second "Spring/ Summer" season. Income from heating proved to be higher than those from the sale of electricity, and with the season "Spring / Summer" superior to the station "Winter/ Autumn", because its solar radiation in the first season, the collector it is higher, with the intention of not under sizing the system, scaled to the area and the amounts of collectors required to $1044.2 \mathrm{~m} 2$ and 590 collectors. The total income obtained was estimated at 48360 $€ /$ year and the total investment value with collectors in $243746.7 €$. Taking into account the profit from the sale of electricity and what is earned by the consumer does not have cost the gas, the investment made with the vacuum tube solar collectors is amortized over eight years.

This work contributes to assimilation and deepening of theoretical concepts related to the thermodynamics and acquired throughout my academic career to the schedule. With this knowledge, I fulfilled a model and computer program for the study of a solar system ORC, with which any user can perform a simple analysis at the level of behaviour of a solar thermal collector, over the inserted gross solar radiation input and the desired operating characteristics of the collector. On the other hand, can also be checked the thermodynamic performance of the system in relation to the desired power output of the turbine, the fluid type and operating conditions. In this way, the user is lucid for the best operating conditions to be subject the system, the amount and area of collectors' necessary, a possible actual implementation.
In short, with the model and computer program developed, I provide the possibility for the user, free of charge; conduct a quick pre-analysis, without loss of time and which can distinguish what is feasible from what is not feasible to their study without the need to purchase the equipment.

With analysis on the type of solar systems studied in this work, I found that the impact of the provided radiation and the parameters that affect the performance of the solar heat collector vacuum tube used. For the desired power of $10 \mathrm{KW}$ and making the cycle operating with the fluid type R-245fa, including the best operating conditions, the area and the number of collectors necessary and what is the payback investment with their collectors by its implementation.

\section{Acknowledgement}

This work has been supported by COMPETE: POCI01-0145-FEDER-007043 and FCT - Fundação para a Ciência e Tecnologia within the Project Scope: UID/CEC/00319/2013.

\section{References}

[1] Fialho, P. Gross incident radiation data on Terceira Island. Green Islands Azores Project.

[2] Nafey, AS, \& Sharaf, MA (2010). Combined solarorganicRankinecyclewithreverseosmosisdes alinationprocess: RenewableEnergy, 35, 25712580.

[3] Delgado-Torres, AM, \& Rodriguez, LG (2010). Analysis and optimization of the lowtemperature solar organic Rankine cycle (ORC). Energy Conversion and Management, 51, 28462856.

[4] Matlab R2008a, v. 7. 7.

[5] Astolfi, M. Xodo, L. Romano, MC, \& Macchi, E. (2011). Technical and economical analysis of solar-geothermal hybrid plant based on. Geothermics, 40, 58-68.

[6] Larjola, J. (1995). Electricity from industrial waste heat using high-speed organic. Int. J. Production Economics, 41, 227-235.

[7] Schuster, A., Karellas, S., \& Aumann, R. (2010). Efficiency optimization potential in supercritical Organic Rankine Cycles. Energy, 35, 1033-1039.

[8] Schuster, A. Karellas, S., Kakaras, E., \& Spliethoff, H. (2009). Energetic and economic investigation of Organic Rankine Cycle applications. Applied Thermal Engineering, 29, 1809-1817.

[9] Dai, Y., Wang, J., \& Gao, L. (2009). Parametric optimization and comparative study of organic Rankine cycle (ORC). Energy Conversion and Management, 50, 576-582.

[10] Quoilin, S., \& Declaye, S. (2011). Thermoeconomic optimization of waste heat recovery 
Organic Rankine Cycles. Applied Thermal Engineering, 31, 2885-2893.

[11] Quoilin, S., Orosz, M. Hemond H, \& Lemort, V. (2011). Performance and design optimization of a low-cost solar. Solar Energy, 85, 955-966.

[12] Wang, XD, \& Zhao, L. (2009). Analysis of zeotropic Mixtures used in low- temperature solar Rankine cycles for power generation. Solar Energy, 83, 605-613.

[13] Wang, XD, Zhao, L., \& Wang, JL (2011). Experimental investigation on the lowtemperature solar Rankine cycle. Energy Conversion and Management, 52, 946-952.

[14] Angelino, G., \& Invernizzi, C. (2003). Experimental investigation on the thermal stability of some new zero ODP refrigerants. International Journal of Refrigerantion, 26.

[15] Sacoman, MA, Chueiri, VM, \& Gonçalves, MS (2006). RANKINE CYCLES - A COMPUTER TOOL.

[16] Leão, C.P., Soares, F., Rodrigues, H., Seabra, E., Machado, J., Farinha, P., Costa, S. "Web-assisted laboratory for control education: Remote and virtual environments" (2012) Communications in Computer and Information Science, 282 CCIS, pp. 62-72

[17] Leão, C.P., Soares, F.O., Machado, J.M., Seabra, E., Rodrigues, H. "Design and development of an industrial network laboratory" (2011) International Journal of Emerging Technologies in Learning, 6 (Special Issue 2), pp. 21-26

[18] Pereira, F., Carvalho, V., Soares, F., Machado, J., Bezerra, K., Silva, R., Matos, D. "Development of a Medical Care Terminal for Efficient Monitoring of Bedridden Subjects", (2016) Journal of Engineering (United States), 2016, art. no. 3591059

[19] Campos, J.C., Machado, J., Seabra, E. Property patterns for the formal verification of automated production systems (2008) IFAC Proceedings Volumes (IFAC-PapersOnline), 17 (1 PART 1)

[20] Campos, J.C., Machado, J. "Pattern-based analysis of automated production systems" (2009) IFAC Proceedings Volumes (IFAC-PapersOnline), 13 (Part 1), pp. 972-977

[21] Kunz, G., Perondi, E., Machado, J. "Modeling and simulating the controller behavior of an Automated People Mover using IEC 61850 communication requirements" (2011) IEEE International Conference on Industrial Informatics (INDIN), art. no. 6034947, pp. 603608.

[22] Kunz, G., Machado, J., Perondi, E. “Using timed automata for modeling, simulating and verifying networked systems controller's specifications" (2017) Neural Computing and Applications, 28 (5), pp. 1031-1041.

[23] Campos, J.C., Machado, J. "A specification patterns system for discrete event systems analysis (2013) International Journal of Advanced Robotic Systems, 10, art. no. A315.

[24] Madhawa, H., \& H., D. (2007). Optimum design criteria for an organic Rankine cycle using lowtemperature geothermal heat source. Energy, 32, 1698-1706.
[25] Mills, D. (2004). Advances in solar thermal electricity technology. Solar Energy, 76, 19-31.

[26] Çencel, YA, \& Boles, MA (2007). Thermodynamics (5 ed.). Sao Paulo: McGrawHill.

[27] TZ58-1800. (23 March 2007). Collector test According to EN 12975 to 1.2 : 2006. P. 30.

[28] Rankine cycle (ORC). Energy Conversion and Management, 50, 576-582.

[29] Grebenkov, AJ, \& Beliayera, OV (30 September 2004). Thermophisical properties of R245fa. P. 110.

[30] Decree - Law \# 363/2007. (2 November 2007). Ministry of Economy and Innovation. Diário da República, 1st series - 211.

[31] Decree-Law \# 118-A / 2010. (25 October 2010). Ministry of Economy, Innovation and Development. Official Gazette, 1st series - 207.

[32] Alves, PD Thermodynamic Tables R-234fa fluid, 51-58.

[33] Hahn, B., \& Valentine, DT (2007). Essential Matlab for Engineers and Scientists (3rd ed.). Oxford: Elsevier.

[34] Hanselman, D., \& Littlefield, B. (2005). Mastering Matlab 7. New Jersey: Pearson Prentice Hall.

[35] Morais, V., \& Vieira, C. (2006). 7 \& Matlab 6: Complete Course (3rd ed.). Lisbon: FCA.

[36] New legislation microgeneration. (sd). Retrieved on 17 October 2011, of enerwise.pt: http://www.enerwise.pt/index.php?id=21.

[37] Çencel, YA (2006). Heat and Mass Transfer: A Practical Approach (3rd ed.). Singapore, McGraw - Hill.

[38] Roy, JP Mishra, MK, \& Misra, A. (2011). Performance Analysis of an Organic Rankine Cycle with superheating under. Applied Energy.

[39] Saleh, B. Koglbauer, \& Gerald. (2007). Working fluids for low-temperature organic Rankine cycles. Energy, 32, 1210-1221.

[40] Santos, J. (2008). Studies of solar thermal systems, Integrated MA graduate in Mechanical Engineering. University of Porto, Portugal.

[41] Stine WB, \& Harrigan, RW (1985). Solar Energy Fundamentals and Design. John Wiley and Sons, Inc., 297.

[42] Yamaguchi, H., Zhang, XR, \& Fujima, K. (2006). Solar energy powered Rankine cycle using supercritical CO2. Applied Thermal Engineering, 26, 2345-2354.

[43] Rodrígueza, LG, \& Gálvez, JB (2007). Solarheated [1] Rankine cycles for water and electricity. Desalination, 212, 311-318.

[44] Rayegan, RY (2011). The procedure to select working fluids for Solar Organic Rankine Cycles (ORCS). Renewable Energy, 36, 659-670.

[45] Wang, XD, Zhao, L., \& Wang, JL (2010). Performance evaluation of a low-temperature solar Rankine. Solar Energy, 84, 353-364.

[46] Moran, MJ, \& Shapiro, HN (2010). Fundamentals of Engineering Thermodynamics (6th ed.). Asia: John Wiley \& Sons. 